\title{
Aurélia Gaillard, Le corps des statues. Le vivant et son simulacre à l'âge classique (de Descartes à Diderot)
}

\section{Franca Zanelli Quarantini}

\section{(2) OpenEdition}

\section{Edizione digitale}

URL: https://journals.openedition.org/studifrancesi/37732

DOI: 10.4000/studifrancesi.37732

ISSN: 2421-5856

Editore

Rosenberg \& Sellier

\section{Edizione cartacea}

Data di pubblicazione: 15 décembre 2004

Paginazione: 613

ISSN: 0039-2944

\section{Notizia bibliografica digitale}

Franca Zanelli Quarantini, «Aurélia Gaillard, Le corps des statues. Le vivant et son simulacre à l'âge classique (de Descartes à Diderot)», Studi Francesi [Online], 144 (XLVIII | III) | 2004, online dal 30 novembre 2015, consultato il 08 mai 2021. URL: http://journals.openedition.org/studifrancesi/37732 ; DOI: https://doi.org/10.4000/studifrancesi.37732

Questo documento è stato generato automaticamente il 8 mai 2021.

\section{(c) $($ ) $\odot$ (8)}

Studi Francesi è distribuita con Licenza Creative Commons Attribuzione - Non commerciale - Non opere derivate 4.0 Internazionale. 


\title{
Aurélia Gaillard, Le corps des statues. Le vivant et son simulacre à l'âge classique (de Descartes à Diderot)
}

\author{
Franca Zanelli Quarantini
}

\section{NOTIZIA}

AURÉLIA GAILLARD, Le corps des statues. Le vivant et son simulacre à l'âge classique (de Descartes à Diderot), Paris, Champion, 2003 («Les Dix- Huitièmes siècles»), pp. 340.

1 Luogo d'incontro della superstizione arcaico-religiosa e di un immaginario fortemente attratto dal principio della somiglianza, il 'corpo della statua' si è da sempre offerto alle metamorfosi più conturbanti: che dal divino e dall'invisibile conducono all'umano, per dare forma corporea al Sacro o alle ombre dei morti (come quella del Commendatore, che si vendica di Don Giovanni), non senza talvolta procedere all'inverso, trasformando il freddo della pietra nel calore accogliente della carne. È quanto mostra, in chiave moderna, il caso freudiano della Gradiva: dove il bassorilievo della figura femminile anticipa e prepara, nei sogni 'pietrificati' (o censurati) di Hanold, l'incontro con Zoe, la fanciulla reale. Come bene osserva l'A., Hanold in sostanza non fa che ripetere il mito di Pigmalione, l'artista innamorato della fanciulla da lui stesso scolpita nell'avorio, e che per un benevolo dono di Afrodite un giorno gli si offri in forma vivente. Transitando attraverso miti molteplici, il tema si arricchisce e si complica: dalla Gorgone, maschera orrifica dal potere pietrificante, a Gige, che vede non visto, la statua chiama a sé i misteriosi attributi delle entità riemerse che, immobili e cieche, 'vedono' dalla morte. Ma è tra Sei e Settecento che, in parallelo alla crescente attenzione scientifica intorno alla natura umana e alla sua condizione corporea e sensoriale, la 'statua' comincia a collocarsi centralmente nell'immaginario francese: si pensi alla ripresa da parte di Rousseau, Condillac, Buffon e Diderot del mito di un Pigmalione ora 'philosophe' ora parodico ora in fusione con un altro grande sogno illuminista, quello dell'"enfant de la nature'. Ma già la mitologia antica abbonda in straordinari effetti di mutazione, in 
grado di imprimere alle storie un dinamismo tutto particolare: ed è precisamente la ripetitività del processo di animazione/pietrificazione (o viceversa) a costituire in definitiva la sola struttura comune a un materiale eterogeneo (letterario, pittorico, paesaggistico, decorativo) su cui l'A. conduce una lettura rigorosa ed avvincente, spaziando dagli 'automates' e 'androïdes' al mondo delle marionette, dall'irrefrenabile e sensualista Pigmalione sadiano, Franval, alle statue di La Fontaine, dai giardini di Versailles ai quadri di Poussin, dalle conturbanti metamorfosi delle statue che popolano le 'féeries' di Mme d'Aulnoy agli squelettes anatomici, tacitamente presenti in ogni corpo scolpito. 